\title{
Desenvolvimento de ferramenta para diagnóstico ambiental de lixões de resíduos sólidos urbanos no Brasil
}

\author{
Development of tool for environmental \\ assessment of municipal solid waste dumps in Brazil
}

\begin{abstract}
Naiara Francisca Ramos', Juliano Cunha Gomes², Armando Borges Castilhos Jr. ${ }^{3}$, Rémy Gourdon ${ }^{4}$
\end{abstract}
口

\begin{abstract}
RESUMO
Uma realidade ainda muito comum nos países em desenvolvimento é a utilização de lixões como forma de destinação final de resíduos sólidos urbanos, implicando em consequências como contaminação dos recursos naturais e problemas de saúde pública. Assim, torna-se urgente a efetivação das políticas públicas, de modo a promover a destinação adequada dos resíduos sólidos urbanos e a remediação dos lixões. Nesse sentido, este artigo teve como objetivo desenvolver uma ferramenta de apoio à decisão, com a finalidade de auxiliar os municípios brasileiros no diagnóstico de seus lixões, os quais devem funcionar de forma a estabelecer prioridades de remediação. A ferramenta foi construída em três etapas: 1) elaboração de um questionário de campo para diagnosticar lixões; 2) estabelecimento de um sistema de pontuação para o questionário de campo, visando mensurar o nível de impacto de cada lixão diagnosticado;3) Codificação da ferramenta na forma de um programa e de testes de validação. O usuário fornece as informações do formulário de campo para o programa calcular a pontuação, estabelecer o nível de impacto e gerar o diagnóstico do lixão. A ferramenta foi aplicada em quatro lixões, que serviram como objetos do estudo de caso. Mesmo com as poucas informações disponíveis sobre os lixões diagnosticados, os resultados demonstraram que a ferramenta é capaz de atingir seus objetivos, contribuindo para a melhoria da gestão de resíduos sólidos no Brasil.
\end{abstract}

Palavras-chave: lixões; remediação de lixões; avaliação ambiental.

\begin{abstract}
The use of landfills as means of disposal of municipal solid waste is a very common reality in developing countries, resulting in consequences such as contamination of natural resources and public health problems. Thus, it is urgent to improve the effectiveness of public policies, in order to promote the proper disposal of municipal solid waste and remediation of landfills. In this sense, this paper aimed to develop a tool for decision support intended to assist municipalities in assessing its landfills in order to establish remediation priorities. The tool was developed in three stages: 1) development of a field survey to diagnose dumps sites; 2) establishment of a scoring system for the field survey, aiming to measure the level of impact of each diagnosed dumpsite; 3) Codification of the tool into a program and validation test. The user input information from the field form, then the program calculate the punctuation, establish the level of impact and generate the dumpsite's diagnostic. The tool was applied in four open dumps, which served as case studies. The results showed that the tool is able to achieve its goals, contributing to the improvement of waste management in Brazil, even with the limited information available on the diagnosed dump sites.
\end{abstract}

Keywords: Illegal dumping sites; remediation of old dump sites; environmental assessment.

口-

\section{INTRODUÇÃO}

O crescimento exponencial da população, juntamente com o processo de industrialização ao longo da história, resultou em problemas de proporções globais, a exemplo da rápida urbanização,

da limitação de recursos naturais e da grande geração mundial de Resíduos Sólidos Urbanos (RSU). Segundo Nagashima et al. (2011), entre 1979 e 1990, a geração de RSU cresceu a uma taxa de 25\%, sendo superior ao crescimento populacional em nível mundial, que

'Doutoranda em Engenharia Ambiental pela Universidade Federal de Santa Catarina (UFSC) - Florianópolis (SC), Brasil. Bióloga pela Universidade Estadual de Ponta Grossa (UEPG) - Ponta Grossa (PR), Brasil.

${ }^{2}$ Mestrando em Engenharia Ambiental pela Universidade Federal de Santa Catarina (UFSC) - Florianópolis (SC), Brasil. Engenheiro Ambiental pela Universidade do Extremo Sul Catarinense (UNESC) - Criciúma (SC), Brasil. Professor do Instituto Federal de Santa Catarina (IFSC) - Xanxerê (SC), Brasil.

${ }^{3}$ Professor da Universidade Federal de Santa Catarina (UFSC) - Florianópolis (SC), Brasil. Doutor em Gestão e Tratamento de Resíduos Solídos pelo Institut National Des Sciences Appliquées - Lyon, França.

${ }^{4}$ Professor pesquisador do Institut National des Sciences Appliquées - Lyon, França.

Endereço para correspondência: Naiara Francisca Ramos - Depto. de Eng. Sanitária e Ambiental Centro Tecnológico - CTC - Universidade Federal de Santa Catarina Campus Universitário - Trindade - Rua Delfino Conti, 476 - 88040-970 - Florianópolis (SC), Brasil - E-mail: naiara.francisca@gmail.com

Recebido em: 27/06/16 - Aceito em: 11/11/16 - Reg. ABES: 165817 
foi de $18 \%$ no mesmo período. Já o Brasil, somente no ano de 2013, produziu 76,4 milhões de toneladas de resíduos e, no ano seguinte, gerou 78,5 milhões de toneladas.

Monteiro et al. (2001) definiram os lixões como locais onde os RSU são dispostos diretamente sobre o solo sem nenhuma forma de controle ambiental, contaminando-o bem como contaminando o ar, a água superficial e a subterrânea. Assim, proliferam os vetores de doenças e os lixões atraem pessoas em condição de vulnerabilidade social, as quais passam a "catar" o lixo, como forma de sobrevivência, e a viver nas proximidades.

Pode ser vista na Tabela 1 a quantidade de municípios brasileiros que destinaram seus RSU em locais adequados (aterros sanitários) e não adequados (aterros controlados e lixões), entre os anos de 2011 e 2014. Atualmente, $28 \%$ dos municípios destinam seus RSU a lixões, $32 \%$ a aterros controlados e $40 \%$ a aterros sanitários; ou seja, $60 \%$ dos municípios brasileiros ainda destinam seus resíduos a locais inadequados (ABRELPE, 2013; 2015).

A preocupação com as áreas degradadas por resíduos surgiu nos Estados Unidos, na década de 1980, porém tendo como foco principal as áreas contaminadas por resíduos perigosos. Assim, em atendimento à lei americana - conhecida como Comprehensive Environmental Response, Compensation, and Liability Act (CERCLA) - a United States Environmental Protection Agency (USEPA) elaborou um guia conduzindo investigações e processos de recuperação de áreas degradadas por resíduos perigosos. Tal guia serviu ao desenvolvimento de diversos outros materiais relacionados à temática no mundo todo (ADEME, 2005; AFCEE, 1999). No Brasil, o guia da USEPA trouxe elementos para a elaboração do Manual de gerenciamento de áreas contaminadas da Companhia Ambiental do Estado de São Paulo (CETESB, 2001b) e para a elaboração das resoluções do Conselho Nacional do Meio Ambiente (CONAMA) no 420/2009 (BRASIL, 2009) e CONAMA n ${ }^{\circ}$ 001/86 (BRASIL, 1986). Igualmente, destaca-se o guia Caderno técnico de reabilitação de áreas degradadas por resíduos sólidos urbanos, da Fundação Estadual de Meio Ambiente de Minas Gerais (FEAM, 2010).

Tabela 1 - Destinação Final de RSU no Brasil, entre 2011 e 2014.

\begin{tabular}{l|c|c|c|c|c}
\multicolumn{2}{c}{} & \multicolumn{4}{c}{ Ano } \\
\cline { 3 - 6 } Destino Final & 2011 & 2012 & 2013 & 2014 \\
\cline { 3 - 6 } & Aterro sanitário & 2.194 & 2.213 & 2.226 & 2.236 \\
\cline { 2 - 6 } $\begin{array}{l}\text { Número de } \\
\text { municípios }\end{array}$ & Aterro controlado & 1.764 & 1.773 & 1.775 & 1.775 \\
\cline { 2 - 6 } & Lixão & 1.607 & 1.579 & 1.569 & 1.559 \\
\cline { 2 - 6 } & Total de municípios & 5.565 & 5.565 & 5.570 & 5.570 \\
\hline \multirow{3}{*}{\begin{tabular}{l} 
municípios \\
\cline { 2 - 6 }
\end{tabular}} & Aterro sanitário & $39 \%$ & $40 \%$ & $40 \%$ & $40 \%$ \\
\cline { 2 - 6 } & Aterro controlado & $32 \%$ & $32 \%$ & $32 \%$ & $32 \%$ \\
\cline { 2 - 6 } & Lixão & $29 \%$ & $28 \%$ & $28 \%$ & $28 \%$ \\
\hline
\end{tabular}

Fonte: adaptado de ABRELPE (2013; 2015).
Finalmente, foi instituída no Brasil a Política Nacional de Resíduos Sólidos (PNRS), por meio da Lei $\mathrm{n}^{\circ}$ 12.305, de 2 de agosto de 2010, que previa a disposição final ambientalmente adequada dos resíduos em até quatro anos após sua publicação, implicando na remediação e eliminação dos lixões. Todavia, o Senado Federal Brasileiro aprovou o projeto de Lei $n^{\circ} 425$ de 2014, prorrogando os prazos da disposição adequada dos resíduos sólidos para até 31 de julho de 2021. (BRASIL, 2010a; 2010b; ALTAFIN, 2014).

Nesse contexto, o processo de remediação compreende um conjunto de técnicas usadas na remoção ou contenção de contaminantes em áreas degradadas, visando sua reabilitação para posterior uso (SÁNCHEZ, 2008). Na medida em que a maioria dos municípios brasileiros de pequeno porte não possui equipe técnica para diagnosticar seus lixões e estabelecer prioridades de remediação, uma ferramenta de apoio à decisão (FAD), de fácil utilização, é uma alternativa importante para suprir tal necessidade. A Figura 1 ilustra as etapas para a remediação e a eliminação de lixões de RSU.

De acordo com Morrissey e Browne (2004), as primeiras pesquisas com a finalidade de criar FADs remontam às décadas de $1970 \mathrm{e}$ 1980, e eram focadas na minimização dos custos na gestão dos resíduos mistos e recicláveis. Entre o final da década de 1980 até o final da década de 1990, os conceitos de gestão integrada de RSU e avaliação de ciclo de vida foram inseridos nas ferramentas. Até esse período, havia pouca literatura sobre o assunto. Porém, foi a partir dos anos 2000 que as FADs começaram a prever os diversos indicadores sociais, ambientais e econômicos com análise multicritério, como é o caso da FAD desenvolvida por este grupo de pesquisa e apresentada neste trabalho.

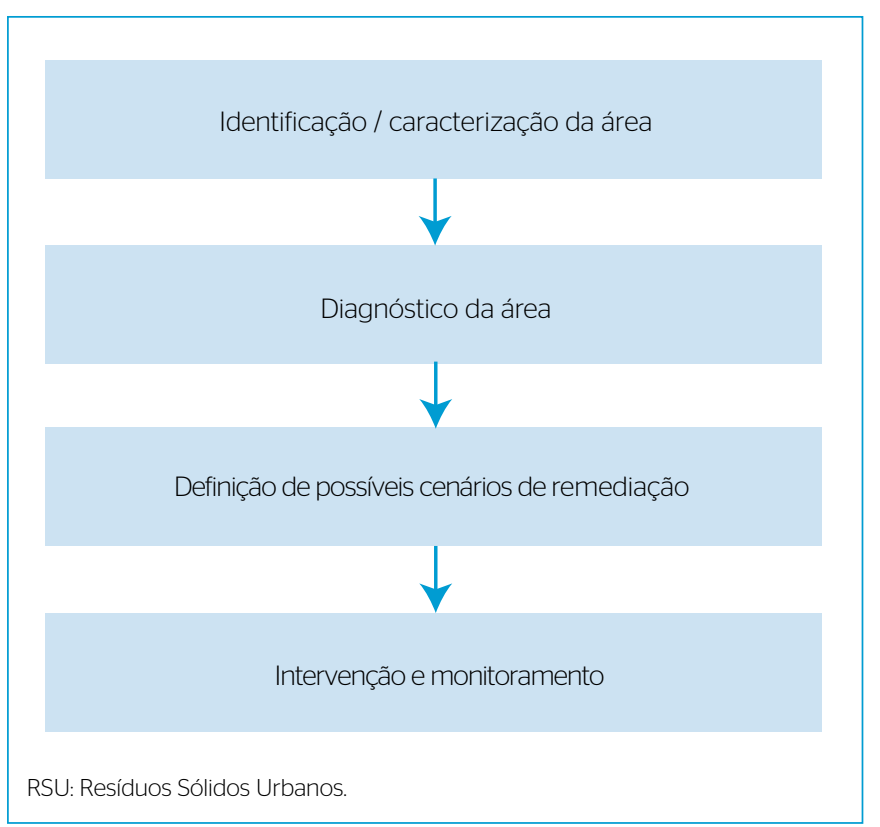

Figura 1 - Etapas para a remediação de lixões de RSU. 


\section{METODOLOGIA}

A FAD foi construída em três etapas:

1. elaboração de um questionário de campo para diagnosticar lixões;

2. estabelecimento de um sistema de pontuação para o questionário de campo, visando mensurar o nível de impacto de cada lixão diagnosticado;

3. codificação da ferramenta na forma de um programa. Ao final do desenvolvimento do programa, este foi validado por usuários, os quais inseriram as informações do formulário de campo e o programa efetuou os cálculos da pontuação. Por meio desses dados, o programa estabeleceu o nível de impacto e gerou o diagnóstico do lixão. Cada etapa do processo será mais detalhada a seguir.

\section{Elaboração do Questionário de Campo}

A elaboração do questionário baseou-se em diversos trabalhos nacionais e internacionais, incluindo leis e normas brasileiras, tais como: ADEME (2005), CETESB (2001a; 2001b; 2014), FEAM (2010), Oliveira e Azevedo (2010); Rechert (2007), Possamai et al. (2007), Pereira (2005), Tchobanoglous, Theissen e Eliassen (1982), USEPA (1988), CPRM (2011), ABNT (1992; 1997) e Brasil (2005; 2008; 2009; 2010a; 2012).

O questionário foi composto por seis categorias definidas da seguinte forma:

1. Caracterização do lixão;

2. Solo e águas subterrâneas;

3. Águas superficiais;

4. Meio social;

5. Meio natural e paisagens;

6. Meio atmosférico.

As categorias foram formadas por um número variável de questões e de possíveis respostas, ordenadas da menor para a maior pontuação, considerando que, quanto menor a pontuação final, menor é seu nível de impacto. A Figura 2 ilustra esse processo, onde se verifica que, na questão "4.1 Densidade populacional em um raio de 500 m" da categoria "4. MEIO SOCIAL", a primeira resposta possui impacto menor em relação à última. Essa lógica serve para todo o questionário.

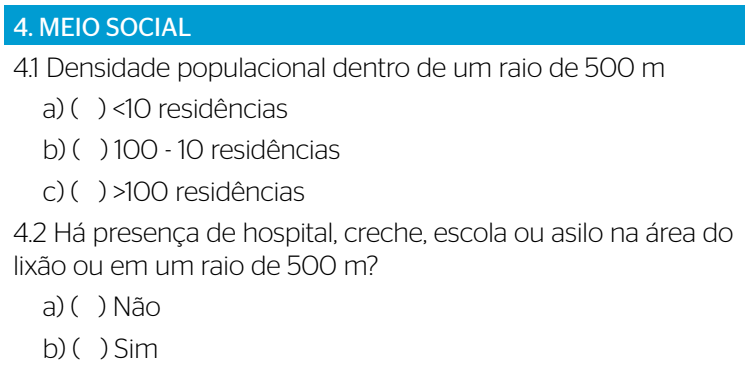

Figura 2 - Exemplo de categoria, questão e opções de respostas para o diagnóstico de lixões.
Para a avaliação do questionário, formou-se um grupo de 15 especialistas com conhecimentos específicos na área de resíduos sólidos que responderam questões sobre o alcance dos objetivos propostos e a pertinência e/ou a ausência de questionamentos. Após a análise dessas contribuições, o questionário passou pela etapa de ponderação de suas categorias de acordo com seis situações genéricas ilustradas na Figura 3:

1. Área protegida por lei;

2. Área urbana ou rural;

3. Área em talvegue que pode abrigar curso d'água intermitente;

4. Área em região de várzea;

5. Área de recarga de manancial;

6. Área industrial.

A etapa de ponderação foi efetuada com base na metodologia proposta por Schmid (2012), na qual cada especialista consultado atribui um percentual relativo à importância de cada categoria dentro de cada situação específica. Utilizou-se, para a atribuição final, a média do grau de importância atribuído pelos especialistas, conforme apresentado na Tabela 2.

A Tabela 2 ilustra o arredondamento da média aritmética dos valores atribuídos pelos especialistas a cada categoria em função da situação. É possível perceber, por exemplo, que no meio social, um lixão tem mais impacto se estiver em área urbana (situação 2) do que se estiver em área rural (situação 1).

\section{Estabelecimento do Sistema de Pontuação}

Como existe uma variação na quantidade de respostas nas questões do questionário de campo, foi preciso normalizar os valores das respostas para tornar o peso das questões equivalentes. Como o número máximo possível de respostas $\left(\mathrm{N}_{\max }\right)$ no questionário é seis, a normalização dos valores foi feita dividindo esse número pelo número de respostas da questão $\left(\mathrm{N}_{\mathrm{r}}\right)$. Isso foi feito por meio da equação do valor de normalização $\left(\mathrm{V}_{\mathrm{n}}\right)$, expressa (Equação 1):

$\mathrm{V}_{\mathrm{n}}=\frac{\mathrm{N}_{\max }}{\mathrm{N}_{\mathrm{r}}}$

Partindo do valor de normalização $\mathrm{V}_{\mathrm{n}}$, obtém-se o valor de cada resposta multiplicando sua posição na ordem de possíveis respostas da questão por $\mathrm{V}_{\mathrm{n}}$. Com isso, conseguiu-se atribuir um valor a cada resposta do questionário, de forma que todas as questões tivessem valor máximo seis para a resposta de maior impacto, e que o valor decrescesse linearmente para as respostas de menor impacto, conforme o número de respostas possíveis. Por exemplo, na Figura 2, a questão 4.1 possui três possibilidades de resposta, enquanto a questão 4.2 possui duas possibilidades de resposta. Aplicando a equação $V_{n}$ em ambas as questões, chegou-se aos valores expressos na Tabela 3. 
O cálculo do sistema de pontuação é feito primeiramente verificando a ocorrência de cada situação ilustrada na Figura 2. Quando a condição for verdadeira, deve-se buscar na Tabela 2 o valor de cada situação em cada categoria (exemplo: $\mathrm{S}_{1} \mathrm{C}_{1}=$ Valor da situação 1 na categoria 1 , neste caso, 16) e multiplicá-lo pelo somatório dos valores das respostas normalizadas de $\left(\Sigma \mathrm{RC}_{1} \ldots \Sigma \mathrm{RC}_{6}\right)$, de forma a obter o somatório das situações na categoria $(\Sigma S C)$. Em seguida, a equação é dividida por 100 para que

Tabela 2 - Valores atribuídos a cada categoria em função da situação.

\begin{tabular}{l|c|c|c|c|c} 
Categoria & $\begin{array}{c}\text { Situa- } \\
\text { ção 1 }\end{array}$ & $\begin{array}{c}\text { Situa- } \\
\text { ção 2 }\end{array}$ & $\begin{array}{c}\text { Situa- } \\
\text { ção 3 }\end{array}$ & $\begin{array}{c}\text { Situa- } \\
\text { ção 4 }\end{array}$ & $\begin{array}{c}\text { Situa- } \\
\text { ção 5 }\end{array}$ \\
\hline $\begin{array}{l}\text { 1) Caracterização do } \\
\text { lixão }\end{array}$ & 16 & 17 & 15 & 13 & 17 \\
\hline $\begin{array}{l}\text { 2) Solo e águas } \\
\text { subterrâneas }\end{array}$ & 23 & 17 & 23 & 25 & 22 \\
\hline 3) Águas superficiais & 22 & 14 & 25 & 28 & 20 \\
\hline 4) Meio Social & 8 & 23 & 9 & 8 & 17 \\
\hline $\begin{array}{l}\text { 5) Meio natural e } \\
\text { paisagens }\end{array}$ & 23 & 13 & 18 & 18 & 13 \\
\hline 6) Meio atmosférico & 8 & 16 & 10 & 8 & 11 \\
\hline
\end{tabular}

seus resultados se mantenham na ordem das dezenas. Isso é feito para cada situação identificada. Por fim, é necessário calcular a pontuação do lixão (PL), somando-se os somatórios $\Sigma$ SC das situações identificadas para o lixão avaliado. A Figura 4 ilustra o processo.

Para definir o nível de impacto de um lixão em função de sua pontuação, foi necessário determinar uma escala numérica (EN), estimando os valores mínimos e máximos que podem ocorrer na pontuação de um lixão. Buscou-se manter a escala no formato inteiro e divisível por três (três níveis de impacto), arredondando valores caso necessário. Os

Tabela 3 - Valores normalizados atribuídos para as questões 4.1 e 4.2 do questionário de campo.

\begin{tabular}{c|c} 
Vn $4.1=6 / 3=2$ & Vn $4.2=6 / 2=3$ \\
Questão 4.1 & Questão 4.1 \\
a) 2 & a) 3 \\
b) $(2+2)=4$ & b) $(3+3)=6$ \\
c) $(2+2+2)=6$ &
\end{tabular}

Vn = valor de normalização; Vn4.1 = valor de normalização da questão 4.1 do questionário de campo; Vn4.2 = valor de normalização da questão 4.2 do questionário de campo.

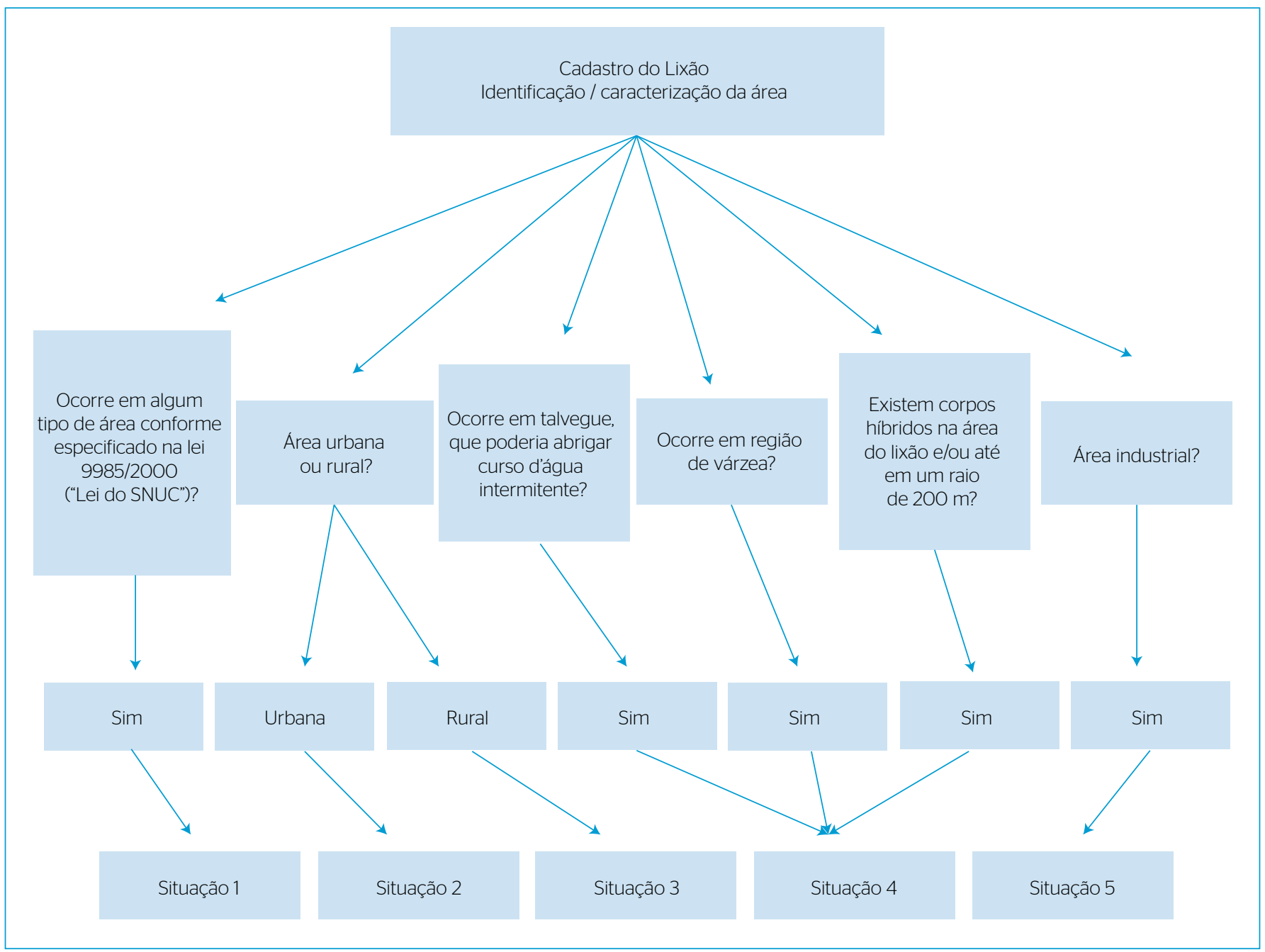

Figura 3 - Situações que podem ocorrer em cada categoria. 
resultados obtidos mostram que a pontuação mínima possível é 17,975 e a máxima é 259,92; assim, chegou-se a três intervalos de 80 (Equação 2):

$\mathrm{EN}=\mathrm{PL}_{(\max )}-\mathrm{PL}_{(\min )}=259,92-17,975=241,945$

$\mathrm{EN}_{\text {(arredondado) }}=240$

$\mathrm{EN}_{(\text {intervalo) }}=\frac{\mathrm{EN}}{3}=\frac{240}{3}=80$

Os níveis de impactos definidos são similares aos propostos pela ADEME (2005). Porém, o estabelecimento do sistema de pontuação pode ser considerado como uma nova abordagem sobre hierarquização dos impactos ambientais em lixões. Para que o diagnóstico não apresente para o usuário apenas números, mas também termos compreensíveis, estabeleceram-se níveis de impacto em função do intervalo da escala numérica (240 pontos). A Tabela 4 ilustra os níveis de impacto conforme o intervalo da escala numérica. Nela, é possível perceber que toda a pontuação $\leq 79$ é considerada como "baixo nível de impacto", toda pontuação $\geq 80 \leq 159$ é considerada "médio nível de impacto", e toda a pontuação $\geq 160$ é considerada "alto nível de impacto". Isso significa que o nível de impacto baixo tem uma amplitude de 61 pontos, o nível de impacto médio tem uma amplitude de 79 pontos, e o nível de impacto alto, uma amplitude de 100 pontos.

Situações diversas podem ocorrer em três níveis de impacto; por exemplo, se o usuário precisar decidir qual a prioridade de remediação entre dois lixões que foram diagnosticados como médio nível de impacto. Nesse caso, a pontuação que os lixões obtiveram no diagnóstico (PL) servirá como critério de desempate. Outra sugestão de como decidir sobre diferentes lixões de

Tabela 4 - Níveis de impacto conforme o intervalo da escala numérica.

\begin{tabular}{l|c|c} 
Nivel de impacto & $\begin{array}{c}\text { Intervalo da escala } \\
\text { numérica }\end{array}$ & Amplitude do intervalo \\
\hline Baixo & $\leq 79$ & $79-18\left(\mathrm{PL}_{(\text {minn }}\right)=61$ pontos \\
\hline Médio & $\geq 80 \leq 159$ & $159-80=79$ pontos \\
\hline Alto & $\geq 160$ & $260\left(\mathrm{PL}_{(\text {máx) }}\right)-160=100$ pontos \\
\hline
\end{tabular}

PL: pontuação do lixão.

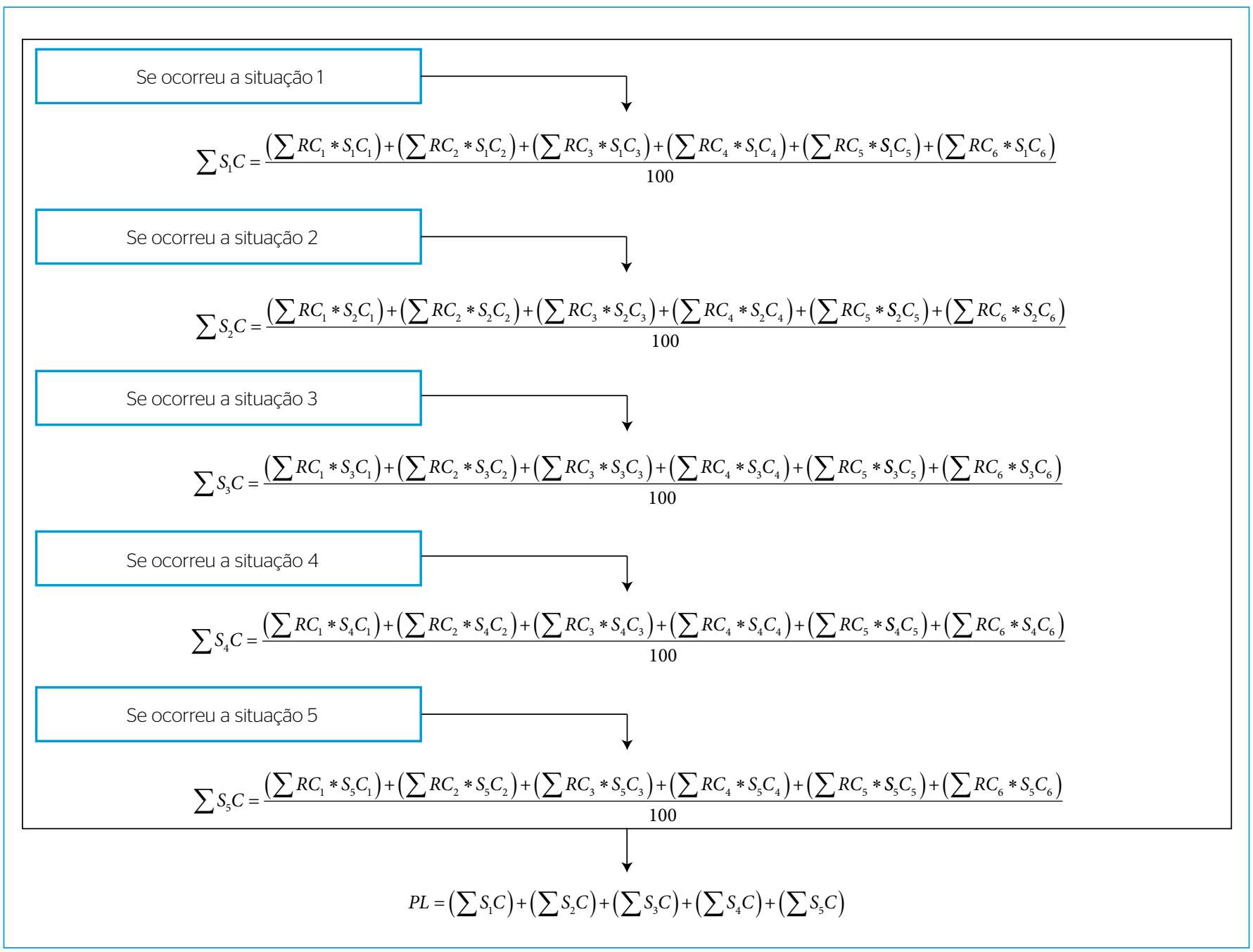

Figura 4 - Cálculo do sistema de pontuação. 
um mesmo nível de impacto seria dividir a amplitude do intervalo por três, o que criaria subdivisões dos níveis de impacto, e aumentaria a sensibilidade que o sistema proporciona. A Tabela 5 ilustra tal processo.

\section{Codificação da Ferramenta e Testes de Validação}

Para a codificação do sistema, foi utilizado o ambiente de programação Qt Creator, com a linguagem de programação C++ e banco de dados SQLite, já que ambos são multiplataforma, programa livre ou Open Source, com documentação de fácil acesso e ampla comunidade de desenvolvedores. Os testes de validação foram feitos primeiramente em laboratório para verificar a correspondência entre o programa e o modelo conceitual estruturado, e em um segundo momento com profissionais da gestão municipal de RSU. O programa desenvolvido e seu código fonte são distribuídos gratuitamente a todos os interessados em utilizá-los ou em colaborar com sua melhoria, podendo ser encontrados no repositório de endereço https://github.com/lareso/DLRSU.

Tabela 5 - Definição das prioridades de recuperação em lixões de mesmo nível de impacto.

\begin{tabular}{|c|c|c|}
\hline Nível de impacto & Divisão da amplitude & Subnivel de impacto \\
\hline \multirow{3}{*}{$\begin{array}{l}\text { Baixo } \\
61 / 3=20,333\end{array}$} & $18+20,333=38,333$ & $\leq 38,333=$ Baixo 1 \\
\hline & $38,333+20,333=58,666$ & $>38,333 \leq 58,666=$ Baixo 2 \\
\hline & $58,666+20,333=78,999$ & $>58,666 \leq 79=$ Baixo 3 \\
\hline \multirow{3}{*}{$\begin{array}{l}\text { Médio } \\
79 / 3=26,333\end{array}$} & $80+26,333=106,333$ & s106,333=Médio 1 \\
\hline & $106,333+26,333=132,666$ & >106,333_132,666=Médio 2 \\
\hline & $132,666+26,333=158,999$ & 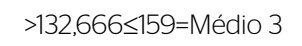 \\
\hline \multirow{3}{*}{$\begin{array}{l}\text { Alto } \\
100 / 3=33,333\end{array}$} & $160+33,333=193,333$ & $\leq 193,333=$ Alto 1 \\
\hline & $193,333+33,333=226,666$ & $>193,333 \leq 226,666=$ =Alto 2 \\
\hline & $226,666+33,333=259,999$ & $>226,666 \leq 260=$ Alto 3 \\
\hline
\end{tabular}

\section{RESULTADOS E DISCUSSÃO}

A fim de validar a ferramenta desenvolvida, a sua versão beta de testes foi aplicada em quatro lixões distribuídos geograficamente da seguinte forma: dois no estado de Santa Catarina (lixões SC1 e SC2), outro no estado do Rio Grande do Sul (lixão RS) e um último no estado de São Paulo (lixão SP). Tais lixões foram selecionados em decorrência da existência prévia de dados sobre essas áreas. Compreendeu-se que a aplicação da ferramenta para a finalidade de validação deveria ser realizada por profissionais que não integraram a etapa de desenvolvimento.

Portanto, participaram da validação quatro profissionais com experiência em remediação de lixões, cada um tendo acesso aos dados documentais necessários e realizando visitas de campo às áreas em estudo. O Quadro 1 apresenta as principais informações referentes à aplicação dos questionários nos lixões e sua análise permite compreender a pontuação e classificação obtidas para cada uma dessas áreas.

Os três níveis de impacto definidos em função da escala numérica, mostrados na Tabela 4, foram estabelecidos, principalmente, para situações onde os municípios ou regiões possuam mais de um lixão diagnosticado pela FAD. O que por sua vez permitiu visualizar de forma rápida os lixões prioritários em termos de remediação.

\begin{tabular}{|c|c|c|c|c|}
\hline ID & Nome & Município & Pontuação & $\begin{array}{l}\text { Nivel de } \\
\text { impacto }\end{array}$ \\
\hline 3 & $\begin{array}{c}\text { Lixão } \\
\text { fictício } 3\end{array}$ & $\begin{array}{l}\text { Município } \\
\text { fictício }\end{array}$ & 186,57 & Alto \\
\hline 1 & $\begin{array}{l}\text { Lixão } \\
\text { fictício } 1\end{array}$ & $\begin{array}{l}\text { Município } \\
\text { fictício }\end{array}$ & 81,94 & Médio \\
\hline 2 & $\begin{array}{l}\text { Lixão } \\
\text { fictício } 2\end{array}$ & $\begin{array}{l}\text { Município } \\
\text { fictício }\end{array}$ & 17,708 & Baixo \\
\hline
\end{tabular}

Figura 5 - Visualização das prioridades de remediação dos lixões diagnosticados em determinado município.

Quadro 1 - Lixões diagnosticados com a FAD.

\begin{tabular}{|c|c|c|c|c|}
\hline Parâmetros & Lixão SC1 & Lixão SC2 & Lixão RS & Lixão SP \\
\hline Duração das atividades & 1974 a 01/09/2005 & $\begin{array}{c}\text { Atividades encerradas } \\
\text { entre } 10 \text { e } 20 \text { anos }\end{array}$ & 01/01/1983 a 31/12/1999 & 01/01/1980 a 01/01/1996 \\
\hline Situação & Área urbana & $\begin{array}{l}\text { Área rural, com presença } \\
\text { de recursos hídricos em } \\
\text { um raio menor que } 200 \mathrm{~m}\end{array}$ & $\begin{array}{l}\text { Area com características } \\
\text { urbanas/industriais, em } \\
\text { região de várzea, com } \\
\text { presença de recursos } \\
\text { hídricos em um raio } \\
\text { menor que } 200 \text { m }\end{array}$ & $\begin{array}{l}\text { Area rural, com recursos } \\
\text { hídricos em um raio } \\
\text { menor que } 200 \text { m }\end{array}$ \\
\hline Área $\left(m^{2}\right)$ & 50.000 a 500.000 & 5.000 a 50.000 & $>500.000$ & 50.000 a 500.000 \\
\hline Tipos de resíduos & $\begin{array}{c}\text { Todos os tipos de resíduos, } \\
\text { inclui (Classe I) }\end{array}$ & $\begin{array}{c}\text { Todos os tipos de resíduos, } \\
\text { inclui (Classe I) }\end{array}$ & $\begin{array}{l}\text { Predominância de } \\
\text { resíduos de Classe II }\end{array}$ & $\begin{array}{c}\text { Presença de todos os tipos } \\
\text { de resíduos }\end{array}$ \\
\hline Pontuação final do lixão (PL) & 83,18 & 68.723 & 104,865 & 92,625 \\
\hline Nível de impacto do lixão & Médio & Baixo & Médio & Médio \\
\hline Subnível de impacto (tabela 5) & Médio 1 & Baixo 3 & Médio 1 & Médio 1 \\
\hline
\end{tabular}

FAD: ferramenta de apoio à decisão; PL: pontuação do lixão. 
Na tela em que o usuário visualiza essas informações, ocorre a indicação do nível de impacto como sendo "Baixo", "Médio" ou "Alto". A Figura 5 ilustra a tela do programa.

A sensibilidade da FAD no estabelecimento das prioridades entre lixões diagnosticados com o mesmo nível de impacto acontece por meio da pontuação obtida. No exemplo da Figura 5, é possível perceber que na quarta coluna (ao lado da palavra "Pontuação") existe uma seta para cima, significando que o usuário ordenou os lixões do "município fictício" por ordem de pontuação decrescente, clicando no rótulo "pontuação". Nesse caso, o "Lixão fictício 3" possui maior prioridade de remediação, seguido do "Lixão fictício 1" e, por fim, o "Lixão fictício 2". No caso da validação da ferramenta proposta, a partir do preenchimento do questionário de campo e posterior inserção das informações no programa, constatou-se que três dos quatro lixões foram classificados com nível médio de impacto ambiental. No entanto, a análise das pontuações geradas pela ferramenta permitiu verificar que o nível de impacto relacionado ao lixão RS é maior do que dos demais e que o lixão SC2 tem o menor nível de impacto. Portanto, em teoria, o lixão RS teria maior prioridade de remediação, seguido pelo lixão SP e, por último, pelo lixão SC2.

O lixão RS, apontado como o mais impactado ambientalmente, teve sua classificação provavelmente devido a algumas informações destacadas: além de acidentes e eventos geotécnicos importantes, como adensamento dos resíduos e erosão do solo, constatou-se também o vazamento de lixiviados. A espessura da camada de resíduos nesse lixão é superior a $10 \mathrm{~m}$, além de apresentar a maior área superficial dentre os três lixões analisados. Comprovou-se contaminação do solo, águas subterrâneas e águas superficiais. Embora ele esteja localizado em uma área de várzea, que, ao mesmo tempo, é classificada como urbana e industrial, com existência de corpos hídricos em um raio inferior a $200 \mathrm{~m}$ de distância do lixão, a densidade populacional é superior a 10 residências em um raio de $500 \mathrm{~m}$ do lixão, e as atividades agropecuárias são frequentes na área. Também se destaca a possibilidade de haver bolsões de gás e/ou de migração de biogás no lixão RS

O lixão SP, da mesma forma que o lixão RS, apresentou a espessura da camada de resíduos superior a $10 \mathrm{~m}$ e também se constatou contaminação das águas subterrâneas e superficiais. A densidade populacional é menor do que 10 residências em um raio de $500 \mathrm{~m}$ do lixão, e a área é frequentemente usada para atividades agropecuárias, embora a presença de odores no lixão seja frequente.

Dos quatro lixões avaliados, o lixão SC1 foi o que mais continha informações, o que inclui um estudo geofísico, além de possuir melhor controle e gerenciamento. Isso se dá, possivelmente, pelo fato de ser administrado pela mesma empresa que possui um aterro sanitário em anexo com o lixão. Esse lixão encontra-se em área rural, sem grande densidade populacional, sendo a área cercada e controlada por vigia. Além disso, ele compartilha com o aterro sanitário uma estação meteorológica e uma estação de tratamento de lixiviado (biológico e físico-químico). O lixão encontra-se coberto de gramíneas, com sistema de drenagem de águas pluviais, sem focos de processos erosivos, com coleta e tratamento parcial de gás e lixiviado. Mesmo assim, a poluição das águas e do solo foi constatada, devido ao descontrole no passado. A pontuação obtida no diagnóstico foi de 68,723. É importante destacar que, mesmo obtendo nível baixo de impacto, o lixão seria classificado como "Baixo 3", de acordo com o Quadro 1.

Dentro da etapa de validação da ferramenta, os especialistas foram convidados a avaliá-la a partir da resposta a seis perguntas apresentadas no Quadro 2.

Quadro 2 - Questionário de avaliação da FAD.

\begin{tabular}{|c|c|c|c|c|}
\hline Pergunta & Lixão SC1 & Lixão SC2 & Lixão RS & Lixão SP \\
\hline $\begin{array}{l}\text { O diagnóstico feito pela } \\
\text { ferramenta é coerente com o } \\
\text { seu diagnóstico? }\end{array}$ & Sim & Sim & Sim & Sim \\
\hline $\begin{array}{l}\text { Quantos lixões você } \\
\text { diagnosticou com a ferramenta? }\end{array}$ & 1 & 1 & 1 & 1 \\
\hline $\begin{array}{l}\text { A ferramenta auxiliou na decisão } \\
\text { das prioridades de recuperação } \\
\text { e eliminação dos lixões? }\end{array}$ & Sim & Sim & $\begin{array}{c}\text { Sim e não. A ferramenta } \\
\text { permite ter ideia } \\
\text { das prioridades, } \\
\text { embora pareça pouco } \\
\text { aprofundada. }\end{array}$ & Sim \\
\hline
\end{tabular}

FAD: ferramenta de apoio à decisão. 
As FADs atuais estão divididas em três categorias segundo Morrissey e Browne (2004):

1. Análise de custo benefício;

2. Análise de ciclo de vida;

3. Uso de técnicas multicritério.

Esta última foi utilizada neste trabalho, observando-se que, entre a diversidade de ferramentas atuais e os diferentes níveis de pré-requisitos exigidos - quais sejam, a complexidade em compreender e operacionalizar as FADs e também a licença (paga ou gratuita) - verifica-se que, muitas vezes, a utilização dessas técnicas é inviável, principalmente para usuários desprovidos de conhecimentos específicos ou de recursos financeiros. Na escolha da metodologia para o desenvolvimento dessa FAD, utilizou-se o conceito daquilo que era considerado necessário, tangível e exequível para o usuário sem conhecimento técnico, priorizando a realidade dos pequenos municípios, resultando em uma nova abordagem sobre hierarquização dos impactos ambientais em lixões no Brasil.

\section{CONCLUSÕES}

A FAD desenvolvida neste trabalho, comparativamente a outras já desenvolvidas, mostra-se de fácil compreensão e operacionalização, assim como objetiva para o diagnóstico e a classificação de lixões. Portanto, ela é mais próxima da realidade nacional, que é marcada pela carência de recursos técnicos e econômicos e de informações gerais sobre a problemática. Mesmo com as poucas informações disponíveis sobre os lixões diagnosticados pelo programa desenvolvido, os fatos acima foram comprovados por profissionais que avaliaram e validaram a ferramenta, pois acreditaram em sua capacidade de atingir seus objetivos, contribuindo para a melhoria da gestão de resíduos sólidos no Brasil, necessitando de poucas alterações para a versão final.

Além do desenvolvimento e da aplicação da FAD em alguns lixões, esta pesquisa possibilitou constatar a carência dos municípios em relação às informações gerais acerca da gestão de resíduos sólidos - como, por exemplo, no que diz respeito à quantidade de lixões que existem no território municipal, à localização exata, ao volume de resíduos depositados neles, entre outros. Além de ser deficitário nos serviços que presta, foi possível perceber que o setor de gestão de resíduos sólidos não é organizado, sobretudo no que se refere à coleta e à destinação adequada dos resíduos e ao fechamento e à remediação de lixões. Vale lembrar que foram visitados ao todo dez lixões para a validação desta ferramenta, mas que em apenas quatro havia dados suficientes para permitir a aplicação da FAD desenvolvida. Isso decorre da relutância em reconhecer a existência do passivo representado pelos lixões, o que faz com que o problema persista de forma mascarada.

Ademais, o que se percebe na prática é que são poucos os lixões que foram efetivamente fechados e, raramente, recuperados, principalmente por questões técnicas e financeiras dos municípios. Geralmente, as ações de recuperação de um lixão contam apenas com uma simples cobertura de terra sobre os resíduos, cercamento, e o posterior abandono da área para o crescimento natural da vegetação. Percebe-se também que é comum a não realização de um adequado diagnóstico ambiental no local em que os lixões estão situados, o que implica em desconhecimento dos riscos à população e ao meio ambiente.

Em relação aos materiais técnicos que foram desenvolvidos no Brasil, há guias ou manuais proponentes de ações para o processo de recuperação de lixões, como é o caso do que foi desenvolvido pela CETESB (2001b) e FEAM (2010). Todavia, esses voltam-se à apresentação de ações e etapas que compõem o processo de recuperação de áreas degradadas, não podendo ser utilizados como uma FAD propriamente dita. Frente ao exposto, a ferramenta exibida neste trabalho visa suprir uma lacuna existente na literatura técnica brasileira relativa à recuperação de lixões e, ao orientar os passos a serem conduzidos, contribuirá na definição das informações a serem coletadas e das fontes consultadas, para então propor uma análise da situação, auxiliando os municípios na implementação da PNRS, sobretudo quanto à tomada de decisão das prioridades de remediação e eliminação de seus lixões.

\section{REFERÊNCIAS}

ABRELPE - Associação Brasileira de Empresas de Limpeza Pública e Resíduos Especiais. (2013) Panorama dos Resíduos Sólidos no Brasil. São Paulo.

ABRELPE - Associação Brasileira de Empresas de Limpeza Pública e Resíduos Especiais. (2015) Panorama dos Resíduos Sólidos no Brasil. São Paulo.

ADEME - Agence de l'Environnement et de la Maîtrise de l'Energie. (2005) Remise en état des décharges: méthodes et techniques. Angers, França: ADEME.
AFCEE - AIR FORCE CENTER FOR ENVIRONMENTAL EXCELLENCE TECHNOLOGY TRANSFER DIVISION. (1999) Decision ToOl for Landfill Remediation. Disponível em: <http://synectics.net/ public/library/StreamResource.axd?DSN=pub\&Mode=Filelmage Inline\&ID=382>. Acesso em: 25 abr. 2014.

ALTAFIN, I.G. (2014) Municípios pedem mais prazo para apresentar planos de gestão e acabar com lixões. Agência Senado. Disponível em: $\quad<$ http://www12.senado.gov.br/noticias/materias/2014/04/02/ municipios-pedem-mais-prazo-para-apresentar-planos-de-gestaoe-acabar-com-lixoes>. Acesso em: 29 jul. 2015. 
ABNT - ASSOCIAÇÃO BRASILEIRA DE NORMAS TÉCNICAS. (1992) NBR 8.419: Apresentação de Projetos de Aterros Sanitários de Resíduos Sólidos Urbanos. Rio de Janeiro, ABNT.

ABNT - ASSOCIAÇÃO BRASILEIRA DE NORMAS TÉCNICAS. (1997) NBR 13.896: aterros de resíduos não perigosos - critérios para projeto, implantação e operação. Rio de Janeiro, ABNT.

BRASIL. (1986) Conselho Nacional do Meio Ambiente (CONAMA). Resolução Conama n. ${ }^{\circ}$ 001, de 23 de janeiro de 1986. Diário Oficial da União. Disponível em: <http://www.mma. gov.br/port/conama/res/res86/res0186.html>. Acesso em: 19 out. 2015 .

BRASIL. (2005) Conselho Nacional do Meio Ambiente (CONAMA). Resolução n.o 357, de 17 de março de 2005. Diário Oficial da União. Disponível em: <http://www.mma.gov.br/port/conama/legiabre. cfm?codlegi=459>. Acesso em: 13 ago. 2014.

BRASIL. (2008) Conselho Nacional do Meio Ambiente (CONAMA). Resolução n.o 396, de 7 de abril de 2008. Diário Oficial da União. Disponível em: <http://www.mma.gov.br/port/conama/legiabre. cfm?codlegi=562>. Acesso em: 13 ago. 2014.

BRASIL. (2009) Conselho Nacional do Meio Ambiente (CONAMA). Resolução n.o 420, de 28 de dezembro de 2009. Diário Oficial da União. Disponível em: <http://www.mma. gov.br/port/conama/legiabre.cfm?codlegi=620 $>$. Acesso em: 17 jan. 2014.

BRASIL. (2010a) Lei n.0 12.305, de 2 de agosto de 2010. Política Nacional de Resíduos Sólidos. Brasilia. Disponível em: <http:/l www.planalto.gov.br/ccivil_03/_ato2007-2010/2010/lei/112305.htm>. Acesso em: 1.0 set. 2015.

BRASIL. (2010b) Senado Federal. Congresso. Senado. Constituição. Projeto de Lei n.o 425, de 7 de julho de 2015. Altera a Lei n. ${ }^{\circ}$ 12.305/10, que institui a Política Nacional de Resíduos Sólidos. Brasilia. Disponível em: <http://www25.senado.leg.br/web/atividade/ materias/-/materia/119536>. Acesso em: 29 abr. 2016.

BRASIL. (2012) Lei n.o 12.651, de 25 de maio de 2012. Diário Oficial da União, Brasília. Disponível em: <http://www.planalto. gov.br/ccivil_O3/_Ato2011-2014/2012/Lei/L12651.htm>. Acesso em: 10 out. 2013.

CETESB - COMPANHIA TECNOLÓGICA DE SANEAMENTO AMBIENTAL. (2001a) Relatório de Estabelecimento de Valores Orientadores para Solos e Águas Subterrâneas no Estado de São Paulo. Relatórios Ambientais. São Paulo. 244p.

CETESB - COMPANHIA TECNOLÓGICA DE SANEAMENTO AMBIENTAL. (2001b) Manual de gerenciamento de áreas contaminadas. São Paulo.

CETESB - COMPANHIA TECNOLÓGICA DE SANEAMENTO AMBIENTAL. (2014) Inventário Estadual de Resíduos Sólidos Urbanos. Disponível em: <http://residuossolidos.cetesb.sp.gov.br/ wp-content/uploads/sites/36/2013/11/residuosSolidos2014.pdf>. Acesso em: 21 set. 2015.
CPRM - SERVIÇO GEOLÓGICO DO BRASIL. (2011) Seleção de municípios críticos a deslizamentos. Disponível em: <http://www. cprm.gov.br/publique/media/apresentacao_susc.pdf>. Acesso em: 20 jun. 2015.

FEAM - FUNDAÇÃO ESTADUAL DO MEIO AMBIENTE. (2O1O) Caderno técnico de reabilitação de áreas degradadas por resíduos sólidos urbanos. Belo Horizonte: FEAM.

MONTEIRO et al. (2001) Manual de Gerenciamento Integrado de Resíduos Sólidos. Rio de Janeiro: IBAM.

Morrissey, A.J. \& Browne, J. (2004). Waste management models and their application to sustainable waste management. Waste Management, Nova York, v. 24, n. 3, p. 297-308. DOI: http://doi. org/10.1016/j.wasman.2003.09.005

NAGASHIMA, L.A.; BARROS JÚNIOR, C.; ARAÚJO, C.C.; SILVA, E.T; HOSHIKA, C. (2O11) Gestão integrada de resíduos sólidos urbanos - uma proposta para o município de Paranavaí, Estado do Paraná, Brasil. Acta Scientiarum Technology, Maringá, v. 33, n. 1, p. 39-47.

OLIVEIRA, M.D. \& AZEVEDO, M.A. (2010) Indicadores ambientais no monitoramento de processos de recuperação de áreas degradadas pela disposição de residuos sólidos. Disponivel em: <http://www.cbcn.org.br/ simposio/2010/palestras/indicadores.pdf?. Acesso em: 07 out. 2013.

PEREIRA, A.V.R.P. (2005) Desenvolvimento de um indicador para avaliação de desempenho de aterro de resíduos sólidos urbanos. 155f. Dissertação (Mestrado em Engenharia Ambiental) - Programa de Pós-Graduação em Engenharia Ambiental, Universidade Federal de Santa Catarina, Florianópolis.

POSSAMAI, F.P.; VIANA, E.; SCHULZ, H.E.; COSTA, M.M.: CASAGRANDE, E. (2007) Lixões inativos na região carbonífera de Santa Catarina: análise dos riscos à saúde pública e ao meio ambiente. Ciência \& Saúde Coletiva, v. 12, p. 171-179.

REICHERT, G.A. (2007) Projeto, operação e monitoramento de aterros sanitários. Apostila da disciplina de Gerenciamento de Resíduos de Sólidos II. Caxias do Sul: Universidade de Caxias do Sul.

SANCHEZ, L.H. (2008) Avaliação de impacto ambiental: conceitos e métodos. São Paulo: Oficina de Textos. 477p.

SCHMID, A. (2012) Valorisation des véhicules hors d'usage (VHU): comparaison multicritère des scénarios de démantelèment par une étude expérimentale menée sur un site industriel de déconstruction-broyage). Thèse (Doctorat en Sciences de l'Envrionnement Industriel et Urbain) - Institut National des Sciences Appliquées, Lyon, France.

TCHOBANOGLOUS, G.T.H.; THEISSEN, H.; ELIASSEN, R. (1982) Desechos sólidos: principios de ingeniería y administración. Traduzido por: Armando Cubillos. Mérida, Venezuela.

USEPA - United States Environmental Protection Agency. (1988) Guidance for Conducting Remedial Investigations and Feasibility Studies under CERCLA. Disponivel em: <http://rais.ornl.gov/ documents/GUIDANCE.PDF>. Acesso em: 18 abr. 2014. 